\title{
Factors associated with acceptance of provider- initiated HIV testing and counseling among pregnant women in Ethiopia
}

This article was published in the following Dove Press journal:

Patient Preference and Adherence

\section{Ketema Bizuwork \\ Gebremedhin' \\ Bingjie Tian ${ }^{2}$ \\ Chulei Tang ${ }^{3}$ \\ Xiaoxia Zhang ${ }^{3}$ \\ Engida Yisma ${ }^{1,4}$ \\ Honghong Wang ${ }^{3}$}

'Department of Nursing and Midwifery, School of Allied Health

Sciences, College of Health Sciences, Addis Ababa University, Addis Ababa, Ethiopia; ${ }^{2}$ Department of General Surgery, Affiliated Huashan Hospital of Fudan University, Shanghai, China; ${ }^{3}$ Department of Fundamental Nursing, Xiangya School of Nursing, Central South University, Changsha, China; ${ }^{4}$ School of Medicine, Robinson Research Institute, The University of Adelaide, Adelaide, SA, Australia
Correspondence: Honghong Wang Department of Fundamental Nursing, Xiangya School of Nursing, Central South University, 172 Tongzipo Road, Changsha 4I00I3, Hunan, China

Email honghong_wang@hotmail.com
Introduction: The global human immunodeficiency virus (HIV) epidemic disproportionately affects sub-Saharan African countries, including Ethiopia. Provider-initiated HIV testing and counseling (PITC) is a tool to identify HIV-positive pregnant women and an effective treatment and prevention strategy. However, its success depends upon the willingness of pregnant women to accept HIV testing.

Objectives: To describe the level of acceptance of PITC and associated factors among pregnant women attending 8 antenatal care clinics in Adama, Ethiopia.

Methods: Trained nursing students and employees from an HIV clinic conducted face-to-face structured interviews in private offices at the clinics from August to September, 2016.

Results: Among the 441 respondents, 309 (70.1\%) accepted PITC. Women with more antenatal care visits (odds ratio $[\mathrm{OR}]=2.59,95 \% \mathrm{CI}: 1.01-6.63$ ), reported better quality of the PITC service (OR $=1.91,95 \%$ CI: 1.19-3.08), and higher level of knowledge on mother-to-child transmission (OR $=1.82,95 \% \mathrm{CI}: 1.03-3.20)$, were more likely to accept PITC, while women who were older in age $(\mathrm{OR}=0.37,95 \% \mathrm{CI}: 0.19-0.74)$ and perceived negative attitudes from their partners toward HIV-positive results $(\mathrm{OR}=0.31,95 \% \mathrm{CI}: 0.10-0.94)$ were less likely to accept the PITC service.

Conclusion: About one-third of pregnant women are not willing to accept PITC. When designing intervention program to improve the acceptance of PITC, we should take into consideration the personal factors, HIV-related knowledge, and attitude of women as well as institutional factors.

Keywords: pregnant woman, HIV, provider initiated HIV testing and counseling (PITC), Ethiopia

\section{Introduction}

Human immunodeficiency virus/acquired-immunodeficiency syndrome (HIV/AIDS) continues to be a major health concern worldwide and the primary cause of death among young adults in Africa. A total of $90 \%$ of HIV infections in children are acquired through mother-to-child transmission (MTCT) in sub-Saharan African countries, where an estimated 1,500,000 women living with HIV become pregnant every year. ${ }^{1,2}$ In Ethiopia, as of 2016, 671,941 people were living with HIV/AIDS, including 109,133 children, with a countrywide HIV prevalence of $1.1 \%{ }^{3}$

There has been a drop in the HIV prevalence in general; however, for pregnant women, after a decrease from $3.55 \%$ in 2007 to $1.1 \%$ in $2009,{ }^{4,5} \mathrm{HIV}$ prevalence increased to $2.1 \%$ in 2012 worldwide. ${ }^{5}$ MTCT is the main transmission route in children $<15$ years old. To prevent the MTCT (PMTCT) of HIV, a nationwide antenatal 


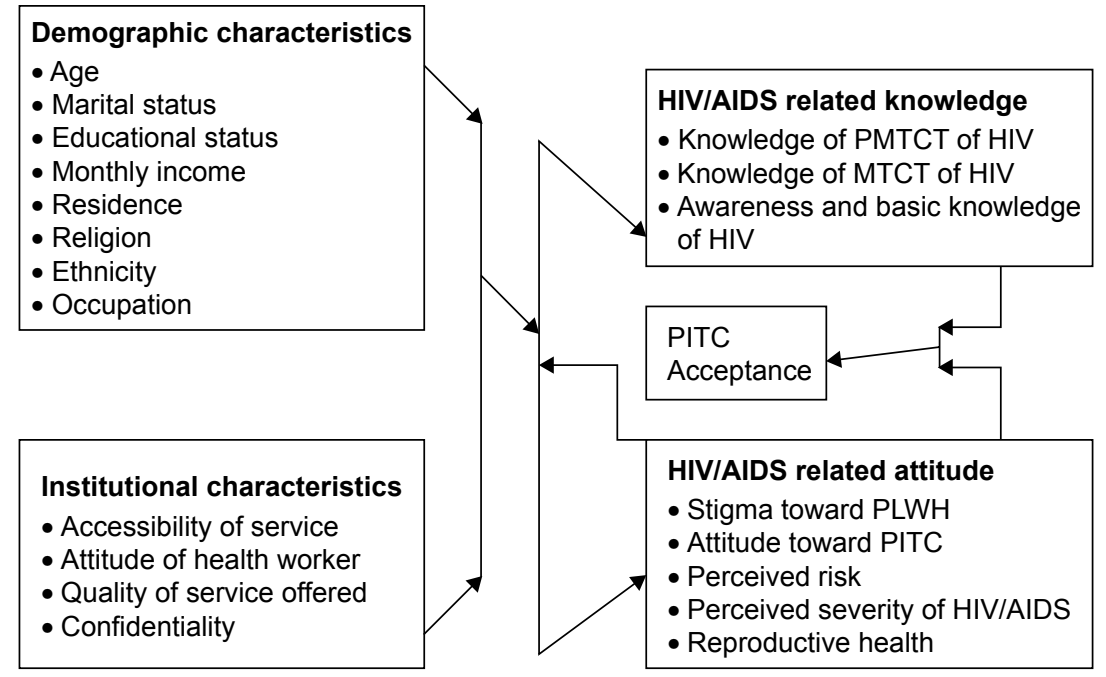

Figure I Factors affecting PITC acceptance.

Abbreviations: AIDS, acquired immunodeficiency syndrome; HIV, human immunodeficiency virus; MTCT, mother-to-child transmission; PITC, provider-initiated HIV testing and counseling; PLWH, people living with HIV; PMTCT, prevention of mother-to-child transmission.

care program was developed worldwide and has now become the largest national antenatal screening program globally. ${ }^{6}$

In Ethiopia, the PMTCT service sites were available in $43 \%$ of all antenatal care facilities, and HIV testing among pregnant women increased from $2 \%$ in 2005 to $26 \%$ in 2010. The percentage of women getting tested remained low compared with the severity of the problem. ${ }^{5}$ Furthermore, the number of HIV-positive pregnant women identified at the PMTCT sites also increased from $1.88 \%$ in 2006 to $22.1 \%$ in 2010. Afterward, the number of pregnant women in need of PMTCT service reached 25,246 , of whom 18,370 needed antiretroviral therapy. ${ }^{3}$ Concurrently, the number of health facilities providing PMTCT service grew from $21.3 \%$ to $61.9 \%{ }^{7}$

Knowing one's HIV status motivates individuals and/or couples to engage in HIV prevention; HIV testing is an obligatory entry point for care and support services for individuals living with HIV/AIDS. ${ }^{8,9}$ Identification of HIV infection in pregnant women is done primarily by voluntary counseling and testing (VCT). ${ }^{10} \mathrm{VCT}$ and guidelines emphasize the importance of confidentiality, voluntary participation, and informed consent, and rely on personal motivation to seek testing.

There are so many obstacles to VCT that only $<10 \%$ of the key populations in low- and middle-income countries who may have been exposed to HIV can access VCT; a majority of the population miss out on opportunities to confirm HIV diagnosis, ${ }^{11}$ especially pregnant women with very low acceptance of VCT. ${ }^{12,13}$ Indeed, only 1 in 5 pregnant women were tested for HIV from 2009 to $2011 .{ }^{14}$ Thus, provider-initiated HIV testing and counseling (PITC) was established by World Health Organization as an HIV testing method to replace
VCT. Nevertheless, only $11 \%$ of pregnant women received HIV testing even after the establishment of PITC in 2011 during antenatal care visits in Ethiopia. ${ }^{10,14}$

PITC is a good entry point for tackling the transmission of HIV from mother to child, even though studies are limited in this area and PITC is not widely accepted in low- and middle-income countries. Studies conducted in other regions of Ethiopia revealed different rates of PITC acceptance with some contradictory factors. . $^{10,15,16}$

In the present study, we explore factors that may hinder or augment PITC in the antenatal care clinics in Ethiopia, with the goal of guiding intervention programs to improve the service delivery system of PITC and PMTCT. Health Belief Model was used in this study as the conceptual framework to reveal health behaviors as the core element of sociodemographic characteristics, knowledge, and perception in people. This model states that people's beliefs influence their behaviors, like developing preventive behaviors against diseases by taking preventive actions in case of acquiring certain diseases and being aware of the severe complications. ${ }^{17}$ Hence, this conceptual framework states socio-demographic factors and institutional factors may influence the individuals to obtain some knowledge of and form correct attitude toward HIV/AIDS, and its transmission and prevention, which may ultimately affect the PITC acceptance (Figure 1).

\section{Methods}

\section{Study design and setting}

In a facility-based cross-sectional study, pregnant women attending antenatal care clinics in Adama, Ethiopia, were interviewed from August to September 2016. Adama is 
$100 \mathrm{~km}$ away from the capital Addis Ababa and has a population of $324,000 .{ }^{18}$ According to the information recorded by the antenatal clinics between the years 2015 and 2016, the HIV prevalence was $2.48 \%$ among pregnant women. ${ }^{19}$ Antenatal care was available to all pregnant women, which included 4 visits: the first visit was as early as suspected pregnancy; the second scheduled between 28 and 32 weeks of gestational age; the third after 36 weeks of gestational age, and the fourth before the expected date of delivery or any time consultancy. All routine antenatal care recommended by WHO would be provided to the pregnant women in the sites.

\section{Recruitment of participants}

Pregnant women aged 15-49 years who received antenatal care services during the study period were included. Those who were critically ill, unable to hear, or with other disabilities such as impaired communication ability, and those who had already received HIV testing during current pregnancy were excluded.

PITC service was provided with informed consent to all pregnant women attending antenatal care facilities per national guidelines. ${ }^{9,20}$ All the health sectors providing qualified PMTCT service in Adama were included in the study. The institutions included 4 governmental health centers, 2 private clinics, 1 private hospital, and 1 governmental hospital. The stratified sampling technique was used to select the study units in each health sector. Based on the number of pregnant women who visited each health sector 10 months before this survey, the total sample size was calculated with a single proportion formula to get the required number of pregnant women from each health sector. Pregnant women were recruited on working days (from Monday to Friday) over a 4-week period.

\section{Study variables and measurement Acceptance of PITC}

The acceptance of PITC was measured by asking 1 question: "Did you take HIV test today?" Women who gave a Yes to the question were regarded as accepting PITC.

\section{Socio-demographic factors}

The socio-demographic factors were obtained from the general information sheet, including age, residence, religion, educational status, occupation, marital status, ethnicity, and monthly income.

\section{Institutional factors}

The institutional factors, including accessibility of service, attitude of health worker, quality of service offered, preference of counselors, and confidentiality condition were measured in the general information sheet.

\section{HIV-related knowledge}

\section{Knowledge about HIV transmission and prevention}

This part of the questionnaire was designed to assess the basic knowledge of HIV transmission and prevention method, such as HIV transmission routes. The knowledge score was assessed with the participant's correct responses. The questionnaire contained 10 items with a total of 40 points. Each correct response got 4 points and a wrong response got 0 .

\section{Knowledge on MTCT of HIV and its prevention}

This part was used to assess the knowledge of pregnant women with regard to MTCT and preventive methods such as hearing about the existence of MTCT and knowing the risk of MTCT during pregnancy, labor, and delivery or breastfeeding. Knowledge about HIV prevention included safe delivery, exclusive breastfeeding for the first 6 months after delivery, taking antiretroviral therapy drugs, and other methods such as HIV testing of infants and HIV-positive mothers administering the antiretroviral drug to their newborns for the first 6 weeks after the delivery. There were 5 questions in this part with a total of 20 points: each correct response got 4 points and a wrong response 0 point.

Modified Bloom's cut-off point was used during analysis, which was adopted from Nyasinde Mujumali's KAP study. A score of $75 \%-100 \%, 50 \%-74 \%$, and $<50 \%$ placed the respondents in good, moderate, and poor HIV/AIDS knowledge groups, respectively. ${ }^{21,22} \mathrm{~A}$ total of 20 items was set to gauge the knowledge of the study participants. Cut-off points for each part are presented in the Table 1.

\section{HIV-related attitude}

This part consisted of 22 items, which included attitude toward PITC, perceived severity of HIV infection, and stigmatizing attitude toward people living with HIV (PLWH). The items were on a 5-point Likert scale. The study participants were asked to respond to what extent they agree with those statements, ranging from strongly agree to strongly disagree and scoring from 5 to 1 , respectively. The total score was calculated by summing up the individual scores of each item. The detailed score cut-off points are described in Table 1.

Five experts, including 2 researchers, 1 lecturer, 1 nursing manager, and 1 registered nurse were invited to review the quality of the questionnaire and evaluate the content validity and this was calculated based on their reports. Accordingly, it was rated at 0.98 with a Cronbach's alpha score of 0.802 .

The interview guide was initially prepared in English and translated into the local languages, Amharic and 
Table I Cutoff points of level of HIV-related knowledge and attitude

\begin{tabular}{llll}
\hline & & Cutoff points & Level \\
\hline Knowledge & HIV transmission and & $30-40$ & Good \\
& prevention & $20-29$ & Moderate \\
& & $<20$ & Poor \\
& MTCT of HIV & $16-20$ & Good \\
& & $12-15$ & Moderate \\
& & $<12$ & Poor \\
Attitude & $16-20$ & Good \\
& & $12-15$ & Moderate \\
& & $<12$ & Poor \\
& & $\geq 25.5$ & Good \\
& & $<25.5$ & Poor \\
& Toward PITC & $\geq 20.88$ & Severe \\
& of HIVIAIDS & $<20.88$ & Not severe \\
& Stigmatizing attitude & $\geq 14.17$ & Had \\
& toward PLWH & $<14.17$ & Did not have \\
& Perceived partner reaction & $\geq 6.8$ & Positive \\
& toward positive result of & $<6.8$ & Negative \\
& HIV/AIDS & & \\
\hline
\end{tabular}

Note: Modified Bloom's cutoff point was used and scores of $75 \%-100 \%, 50 \%-74 \%$, and $50 \%$ placed the respondents in good, moderate, and poor HIVIAIDS knowledge groups, respectively.

Abbreviations: AIDS, acquired-immunodeficiency syndrome; HIV, human immunodeficiency virus; MTCT, mother-to-child transmission; PITC, providerinitiated HIV testing and counseling; PMTCT, prevention of mother-to-child transmission; PLWH, people living with HIV.

Afaan Oromo, and then it was translated back to English to check the comprehension and consistency. As this study was conducted in the city, the majority of people spoke Amharic language in addition to their native language despite their ethnic group difference. Data collectors who spoke both the local languages (Amharic and Afaan Oromo) fluently were recruited and trained for data collection. The completeness of the data collection was checked by the supervisor and investigator on a daily basis. Prior to the date of actual data collection, a pilot test was done on 15 pregnant women and then minor modifications were made and omissions corrected for ambiguous questions based on the pilot test.

\section{Ethical considerations}

The ethical clearance and approval letter were obtained from the Ethical Review Committee of Xiangya School of Nursing, Central South University, China. Based on the ethical approval letter from China, the Ethical Review Committee of Oromia regional health bureau of Ethiopia reviewed and approved this study by an informed letter to the health facilities of the study setting. The health facilities with their own ethical review committee also reviewed and approved the research. Moreover, the verbal consent from the participants was approved by all ethical committees. For participants aged $<18$ years, verbal consent from the mother was obtained, together with assent from the participant before data collection. Furthermore, the nature and purpose of the study were explained to all the participants during the recruitment. The participants had the right to withdraw from the study at any time without getting compensation for the interview.

\section{Data analysis}

The data were edited and cleaned with Epi data version 3.1 software and skipping pattern was kept appropriately. Double entry was done to ensure the accuracy of the database. Data were exported to SPSS Version 23 for data checking, cleaning, and analysis.

Mean, SD, frequency, and percentage were used to describe the data. Univariate analysis was used to determine the association between selected explanatory variables with the outcome variable acceptance of PITC. For those variables significantly associated with one another in the univariate analysis, multivariate logistic regression was used for controlling some potential confounders and checking for their real association independently.

\section{Results \\ Participant description}

Totally, 441 participants were recruited (after the removal of 2 incomplete questionnaires). As seen in Table 2, 86\% of participants were from the urban area. The majority of study participants were from the Oromo ethnic group at $39.9 \%$, with the unemployed reaching $72.1 \%$. The illiteracy rate of the Oromo ethnic group was $9.8 \%$, and $20.16 \%$ of this ethnic group finished grade 1 to 12 , and $9.09 \%$ finished college and higher education. However, among Amhara ethnic group, $3.17 \%$ were illiterate, $18.13 \%$ were educated between grade 1 and 12 , and $7.70 \%$ had passed college and above. The majority of the study participants were young (mean $=26.6$ years). When receiving the interview, 216 (49\%) study participants were in their first antenatal care visit and 222 (50.3\%) were primigravida.

\section{Descriptive data of HIV-related awareness, knowledge, and attitude}

All study participants were aware of HIV/AIDS, and 84.4\% of them had heard of MTCT of HIV. However, only 50.1\% of them knew that the intervention could reduce MTCT of HIV. With regard to knowledge, $54.6 \%$ of the study participants had a moderate knowledge (mean $=5.6, \mathrm{SD}=1.07$ ) of HIV transmission and prevention method. Similarly, $66 \%$ of the sample had good knowledge of MTCT. However, only $13 \%$ had good knowledge of MTCT prevention. Only half 
Table 2 Demographic characteristics and their association with PITC acceptance $(\mathrm{N}=44 \mathrm{I})$

\begin{tabular}{|c|c|c|c|c|c|c|}
\hline \multirow{2}{*}{$\begin{array}{l}\text { Socio-demographic } \\
\text { Variable }\end{array}$} & \multirow[t]{2}{*}{ Frequency (\%) } & \multicolumn{2}{|l|}{ PITC } & \multirow[t]{2}{*}{ OR (95\% Cl) } & \multirow[t]{2}{*}{$\chi^{2}$} & \multirow[t]{2}{*}{$p$-value } \\
\hline & & Acceptors & Non-acceptors & & & \\
\hline \multicolumn{7}{|l|}{ Age (years) } \\
\hline $15-24$ & $175(39.7)$ & 133 & 42 & - & 19.67 & $0.00^{\mathrm{a}}$ \\
\hline $25-34$ & $22 I(50.1)$ & 157 & 64 & & & \\
\hline $35-49$ & $45(10.2)$ & 19 & 26 & & & \\
\hline \multicolumn{7}{|l|}{ Residence } \\
\hline Urban & $379(85.9)$ & 275 & 104 & $2.18(1.26-3.77)$ & 7.98 & $0.00^{\mathrm{a}}$ \\
\hline Rural & $62(14.1)$ & 34 & 28 & & & \\
\hline \multicolumn{7}{|l|}{ Religion } \\
\hline Christian & 304 (68.9) & 209 & 95 & $0.81(0.52-1.28)$ & 0.81 & 0.37 \\
\hline Muslim & I 37 (31.I) & 100 & 37 & & & \\
\hline \multicolumn{7}{|l|}{ Ethnic group } \\
\hline Oromo & $176(39.9)$ & 81 & 47 & - & 6.21 & 0.18 \\
\hline Amhara & I $28(29)$ & 123 & 53 & & & \\
\hline Gurage & $64(14.5)$ & 51 & 13 & & & \\
\hline Tigre & $40(9.1)$ & 30 & 10 & & & \\
\hline Other & $33(7.5)$ & 24 & 9 & & & \\
\hline \multicolumn{7}{|l|}{ Marital status } \\
\hline Married & $34 \mid(77.3)$ & 247 & 94 & $1.61(1.01-2.67)$ & 4.01 & 0.05 \\
\hline Unmarried & $100(22.7)$ & 62 & 38 & & & \\
\hline \multicolumn{7}{|l|}{ Educational status } \\
\hline Illiterate & $88(20)$ & 48 & 40 & - & 20.59 & $0.00^{\mathrm{a}}$ \\
\hline Grade $1-12$ & $253(57.4)$ & 198 & 55 & & & \\
\hline College and above & $100(22.7)$ & 63 & 37 & & & \\
\hline \multicolumn{7}{|l|}{ Occupation } \\
\hline Employed & $123(27.9)$ & 85 & 38 & $0.94(0.60-1.48)$ & 0.08 & 0.78 \\
\hline Unemployed & $318(72.1)$ & 224 & 94 & & & \\
\hline \multicolumn{7}{|c|}{ Average monthly income } \\
\hline$>1,000 \mathrm{ETB}$ & $302(68.5)$ & 221 & 81 & $1.58(1.03-2.43)$ & 4.42 & $0.04^{\mathrm{a}}$ \\
\hline$\leq \mathrm{I}, 000 \mathrm{ETB}$ & $139(31.5)$ & 88 & 51 & & & \\
\hline \multicolumn{7}{|l|}{ Gravidity } \\
\hline One & $222(50.3)$ & 165 & 57 & - & 6.24 & 0.10 \\
\hline Two & $123(27.9)$ & 84 & 39 & & & \\
\hline Three & $63(14.3)$ & 42 & 21 & & & \\
\hline$\geq 4$ & $33(7.5)$ & 18 & 15 & & & \\
\hline \multicolumn{7}{|c|}{ Number of ANC visits } \\
\hline Once & $216(49.0)$ & 123 & 93 & $0.28(0.18-0.43)$ & 34.77 & $0.00^{\mathrm{a}}$ \\
\hline$\geq 2$ & $225(51.0)$ & 186 & 39 & & & \\
\hline
\end{tabular}

Notes: Religion: Christianity, includes Orthodox, Catholic, and Protestant. Marital status: Married refers to formally married and living together, unmarried includes single, divorced and widowed. Illiterate refers to people with no schooling. Occupation: Employed (government and private), unemployed (merchant, housewife, student and other), others in occupation include daily laborers $=3$, on street small trade $=2$, housekeeping work $=2$; Others in ethnicity include Silte $=6$, Somale $=5$, Kafa $=3$, Wolayita $=3$,

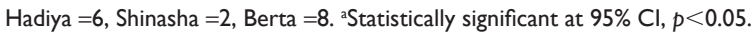

Abbreviations: ANC, antenatal care; ETB, Ethiopian birr; OR, odds ratio; PITC, provider-initiated HIV testing and counseling.

of the pregnant women knew that HIV could be prevented from passing on from mother to child by taking antiretroviral drugs during pregnancy, so could breastfeeding for the first 6 months and safe delivery.

The mean scores were moderate with regard to attitude toward perceived severity of HIV/AIDS, HIV/AIDS-related stigma, and perceived partner reactions toward positive HIV test result. A majority of the participants (61.9\%) reported that they had no stigmatizing attitude toward people living with HIV. More than half of them (54\%) had positive attitude toward PITC. However, 73.5\% reported that their partners would react negatively to positive HIV test result.

\section{Acceptance level of PITC}

Of the total 441 study participants, 309 (70.1\%) accepted PITC, while the rest 132 (29.9\%) rejected it. Generally, PITC was accessible to this sample. Nearly $70 \%$ of the participants heard about PITC before, and $92.1 \%$ reported that they considered they would get benefits from an HIV test. A majority of the participants (81.4\%) reported the health facility nearby 
Table 3 Institutional factors and their association with PITC acceptance (N=44I)

\begin{tabular}{|c|c|c|c|c|c|}
\hline \multirow[t]{2}{*}{ Variable } & \multirow[t]{2}{*}{ Frequency (\%) } & \multicolumn{2}{|l|}{ PITC } & \multirow[t]{2}{*}{$\chi^{2}$} & \multirow[t]{2}{*}{$p$-value } \\
\hline & & Acceptor & Non-acceptor & & \\
\hline \multicolumn{6}{|c|}{ Availability of HIV testing and counseling service nearby } \\
\hline Yes & $359(81.4)$ & 261 & 98 & 9.67 & $0.00^{\mathrm{a}}$ \\
\hline No & $71(16.1)$ & 39 & 32 & & \\
\hline Not sure & II (2.5) & 9 & 2 & & \\
\hline \multicolumn{6}{|c|}{ Access to transport services to visit health facility } \\
\hline Yes & $378(85.7)$ & 287 & 91 & 48.30 & $0.00^{\mathrm{a}}$ \\
\hline No & $54(12.3)$ & 16 & 38 & & \\
\hline Not sure & $9(2.0)$ & 6 & 3 & & \\
\hline \multicolumn{6}{|c|}{ Age preference of the counselor } \\
\hline Similar to my age & $53(12.0)$ & 36 & 27 & 8.83 & $0.03^{\mathrm{a}}$ \\
\hline Younger than my age & $10(2.3)$ & 5 & 5 & & \\
\hline Older than my age & $104(23.6)$ & 84 & 20 & & \\
\hline No age preference & $274(62.1)$ & 184 & 90 & & \\
\hline \multicolumn{6}{|c|}{ Gender preference of the counselor } \\
\hline Male & $48(10.9)$ & 40 & 8 & 5.62 & 0.06 \\
\hline Female & $102(23.1)$ & 74 & 28 & & \\
\hline No gender preference & $291(66.0)$ & 195 & 96 & & \\
\hline \multicolumn{6}{|c|}{ Perceived quality of PITC service } \\
\hline Poor & $24(5.4)$ & 7 & 17 & 66.40 & $0.00^{\mathrm{a}}$ \\
\hline Fair & $70(15.9)$ & 27 & 43 & & \\
\hline Good & 131 (29.7) & 102 & 29 & & \\
\hline Very good & $159(36.1)$ & 127 & 32 & & \\
\hline Excellent & $57(12.9)$ & 46 & 11 & & \\
\hline
\end{tabular}

Note: aStatistical significance at $95 \% \mathrm{Cl}, p<0.05$.

Abbreviations: HIV, human immunodeficiency virus; PITC, provider-initiated HIV testing and counselling.

had PITC. Furthermore, $85.7 \%$ of the study participants had access to transportation to the nearby health center having skilled PITC counselors (Table 3). The women's preference for the counselor was also assessed. A total of $66 \%$ of the study participants accepted both genders as counselors. Similarly, $62.1 \%$ of the study participants responded that they had no preference for the age of a counselor. The percentages of the study participants reporting the quality of PITC services as good, very good, and excellent, were 30\%, 36\%, and $13 \%$, respectively.

\section{Factors related to acceptance of PITC}

Univariate analyses were performed to examine the correlation among acceptance of PITC and demographic factors, institutional factors, and HIV-related knowledge and attitude (Tables 3 and 4). In the demographic data, women's age $\left(\chi^{2}=19.67, p<0.001\right)$, residence $\left(\chi^{2}=7.98, p<0.001\right)$, educational status $\left(\chi^{2}=20.59, p<0.001\right)$, monthly income $\left(\chi^{2}=4.42, p<0.04\right)$, and number of antenatal care visits $\left(\chi^{2}=34.77, p<0.001\right)$ were significantly associated with PITC (Table 2). Among the institutional factors, availability of HIV testing and counseling nearby $\left(\chi^{2}=9.67, p<0.001\right)$, transportation access $\left(\chi^{2}=48.3, p<0.001\right)$, age preference of the counselor $\left(\chi^{2}=8.83, p<0.001\right)$, and perceived quality of PITC service $\left(\chi^{2}=66.4, p<0.001\right)$, were all significantly associated with PITC. Moreover, HIV-related knowledge and attitude, level of knowledge on MTCT of HIV $\left(\chi^{2}=57.08, p<0.001\right)$, stigmatizing attitude toward PLWH $\left(\chi^{2}=11.32, p<0.001\right)$, and perceived partner reaction to positive result $\left(\chi^{2}=34.61, p<0.001\right)$, were all significantly associated with PITC.

Multivariate logistic regression analyses were performed with PITC acceptance as the dependent variable and then significant factors were taken from the univariate analyses as independent variables (Table 5). The results showed that women with more antenatal care visits (odds ratio $[\mathrm{OR}]=2.59$, 95\% CI: 1.01-6.63), reported better quality of the PITC service $(\mathrm{OR}=1.91,95 \% \mathrm{CI}: 1.19-3.08)$, and those with higher level of knowledge on MTCT $(\mathrm{OR}=1.82,95 \% \mathrm{CI}$ : 1.03-3.20), were more likely to accept PITC, while women who were older in age ( $\mathrm{OR}=0.37,95 \% \mathrm{CI}: 0.19-0.74)$ and who perceived the negative partner attitude toward positive HIV result $(\mathrm{OR}=0.31,95 \% \mathrm{CI}: 0.10-0.94)$ were less likely to accept PITC service (Table 6).

\section{Discussion}

This study assessed PITC acceptance and associated factors among pregnant women attending antenatal care clinics in 
Table 4 HIV-related attitude/knowledge and its association with PITC acceptance ( $\mathrm{N}=44 \mathrm{I})$

\begin{tabular}{|c|c|c|c|c|c|c|}
\hline \multirow[t]{2}{*}{ Variable } & \multirow[t]{2}{*}{ Frequency (\%) } & \multicolumn{2}{|l|}{ PITC } & \multirow[t]{2}{*}{ OR $(95 \% \mathrm{Cl})$} & \multirow[t]{2}{*}{$\chi^{2}$} & \multirow[t]{2}{*}{$p$-value } \\
\hline & & Acceptor & Non-acceptor & & & \\
\hline \multicolumn{7}{|c|}{ Attitude towards PITC } \\
\hline Good & $238(54.0)$ & 165 & 73 & $\mathrm{I} .08(0.72-1.63)$ & 0.14 & $0.7 \mathrm{I}$ \\
\hline Poor & $203(46.0)$ & 144 & 59 & & & \\
\hline \multicolumn{7}{|c|}{ Perception of the severity of HIVIAIDS } \\
\hline Severe & $243(55.1)$ & 164 & 79 & $0.76(0.50-1.15)$ & 1.72 & 0.19 \\
\hline Not severe & $198(44.9)$ & 145 & 53 & & & \\
\hline \multicolumn{7}{|c|}{ Stigmatizing attitude toward PLWH } \\
\hline Did not have & $273(61.9)$ & 207 & 66 & $0.49(0.33-0.75)$ & 11.32 & $0.00^{\mathrm{a}}$ \\
\hline Have & $168(38.1)$ & 102 & 66 & & & \\
\hline \multicolumn{7}{|c|}{ Perceived partner reaction to positive result } \\
\hline Positive & $117(26.5)$ & 57 & 60 & $3.68(2.36-5.76)$ & 34.61 & $0.00^{\mathrm{a}}$ \\
\hline Negative & $324(73.5)$ & 252 & 72 & & & \\
\hline \multicolumn{7}{|c|}{ Basic knowledge on HIV transmission and prevention } \\
\hline Poor & $45(10.2)$ & 26 & 19 & & & \\
\hline Moderate & $24 I(54.6)$ & 171 & 70 & - & 3.69 & 0.16 \\
\hline Good & $155(35.1)$ & 112 & 43 & & & \\
\hline \multicolumn{7}{|c|}{ Knowledge on PMTCT } \\
\hline Poor & $74(16.8)$ & 55 & 19 & & & \\
\hline Moderate & $87(19.7)$ & 73 & 14 & - & 5.07 & 0.08 \\
\hline Good & $60(13.6)$ & 41 & 19 & & & \\
\hline \multicolumn{7}{|c|}{ Knowledge on MTCT of HIV } \\
\hline Poor & $92(20.9)$ & 35 & 57 & - & 57.08 & $0.00^{\mathrm{a}}$ \\
\hline Moderate & $58(13.2)$ & 44 & 14 & & & \\
\hline Good & $291(66.0)$ & 230 & 61 & & & \\
\hline
\end{tabular}

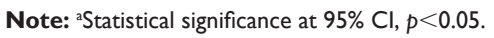

Abbreviations: AIDS, acquired-immunodeficiency syndrome; HIV, human immunodeficiency virus; PITC, provider-initiated HIV testing and counseling; PLWH, people living with HIV; MTCT, mother-to-child transmission; PMTCT, prevention of mother-to-child transmission.

Table 5 Assignments for each potential associated factor of PITC acceptance in multivariate logistic regression

\begin{tabular}{|c|c|c|}
\hline Variable & $\begin{array}{l}\text { Symbol of } \\
\text { variable }\end{array}$ & Assignment \\
\hline Acceptance of PITC & Y & $\mathrm{I}=$ Yes, $0=$ No \\
\hline Age (years) & $\mathrm{X}_{1}$ & $\mathrm{I}=\mathrm{I}-24,2=25-34,3=35-49$ \\
\hline Residence & $\mathrm{X}_{2}$ & $\mathrm{I}=$ Urban, $2=$ Rural \\
\hline Educational status & $\mathrm{X}_{3}$ & $\mathrm{I}=\mathrm{Illiterate}, 2=$ Grade $\mathrm{I}-12,3=$ College and above \\
\hline Average monthly income & $\mathrm{X}_{4}$ & $\mathrm{I}=>\mathrm{I}, 000 \mathrm{ETB}, 2=\leq \mathrm{I}, 000 \mathrm{ETB}$ \\
\hline Number of ANC visits & $\mathrm{X}_{5}$ & $\mathrm{I}=$ Once, $2=$ Twice or above \\
\hline \multirow[t]{2}{*}{ Availability of HIV testing and counseling service nearby } & $X_{61}$ & Yes $=0$, No $=0$, Not sure $=I$ \\
\hline & $X_{62}$ & Yes $=\mathrm{I}$, No $=0$, Not sure $=0$ \\
\hline \multirow[t]{2}{*}{ Access to transport services to visit health facility } & $x_{71}$ & Yes $=0$, No $=0$, Not sure $=1$ \\
\hline & $\mathrm{X}_{72}$ & Yes $=\mathrm{I}, \mathrm{No}=0$, Not sure $=0$ \\
\hline \multirow[t]{2}{*}{ Age preference of the counselor } & $\mathrm{X}_{81}$ & Similar to $\mathrm{my}$ age $=0$, Younger than $\mathrm{my}$ age $=\mathrm{I}$, No age preference $=0$ \\
\hline & $\mathrm{X}_{82}$ & Similar to my age $=\mathrm{I}$, Younger than my age $=0$, No age preference $=0$ \\
\hline \multirow[t]{2}{*}{ Gender preference of the counselor } & $X_{91}$ & Male $=0$, Female $=\mathrm{I}$, Either $=0$ \\
\hline & $X_{92}$ & Male $=\mathrm{I}$, Female $=0$, Either $=0$ \\
\hline Perceived quality of PITC service & $X_{10}$ & $\mathrm{I}=$ Poor, $2=$ Fair, $3=$ Good, 4= Very good, 5= Excellent \\
\hline Stigmatizing attitude towards PLWH/AIDS & $X_{11}$ & $0=$ Not have stigma, $I=$ Have stigma \\
\hline Perceived partner reaction to positive result & $X_{12}$ & $0=$ Negative,$I=$ Positive \\
\hline Knowledge on MTCT of HIV & $X_{13}$ & I= Poor, 2= Moderate, 4= Good \\
\hline
\end{tabular}

Abbreviations: AIDS, acquired immunodeficiency syndrome; ANC, antenatal care; ETB, Ethiopian birr; PITC, provider-initiated HIV testing and counseling; PLWH, people living with HIV; MTCT, mother-to-child transmission. 
Table 6 Multivariate logistic regression analysis of associated factors of PITC acceptance

\begin{tabular}{|c|c|c|c|c|c|c|}
\hline Variable & $\begin{array}{l}\text { Symbol of } \\
\text { variable }\end{array}$ & $\beta$ & SE & Wald $\chi^{2}$ & OR $(95 \% \mathrm{CI})$ & p-value \\
\hline Age & $X_{1}$ & -0.99 & 0.35 & 7.91 & $0.37(0.19-0.74)$ & 0.005 \\
\hline Number of ANC visits & $X_{5}$ & 0.95 & 0.48 & 3.94 & $2.59(1.01-6.63)$ & 0.047 \\
\hline Perceived quality of PITC service & $x_{10}^{3}$ & 0.65 & 0.24 & 7.18 & $1.91(1.19-3.08)$ & 0.007 \\
\hline Perceived partner reaction to positive result & $X_{12}$ & -1.19 & 0.58 & 4.24 & $0.31(0.10-0.94)$ & 0.039 \\
\hline Knowledge on MTCT & $X_{13}$ & 0.60 & 0.29 & 4.27 & $1.82(1.03-3.20)$ & 0.039 \\
\hline
\end{tabular}

Abbreviations: ANC, antenatal care; MTCT, mother-to-child transmission; PITC, provider-initiated HIV testing and counselling; SE, standard error of the mean.

Adama, Ethiopia. The acceptance level of $70.1 \%$ was higher than the HIV testing level of $60.1 \%$ as indicated by the national health survey of Ethiopia in 2011. ${ }^{14}$ This indicates that the progress in scaling up of HIV testing services helps in increasing HIV testing level in Ethiopia. However, still nearly one-third of the study participants were not willing to accept PITC, which was worrisome. Rejecting or delaying HIV testing among the pregnant women suggests the need for intervention program to increase PITC acceptance, which reduces the transmission of HIV from mother to children.

Factors related to PITC acceptance include the age of pregnant women, number of antenatal care visits, perceived quality of PITC service, perceived partner reaction toward the positive result, and level of knowledge on MTCT. The findings are partly consistent with the previous studies. ${ }^{16,23-25}$

We found that younger pregnant women were less likely to accept PITC than older ones, which is similar to other studies in Ethiopia and Cameroon. ${ }^{16,26}$ This is likely because the younger age group in the study participants fear the stigma and discrimination from the society. We also found that the number of antenatal care visits was positively associated with PITC acceptance. Pregnant women with more antenatal care visits tend to have more chances of receiving health education and counseling, which contributes to higher PITC acceptance.

Furthermore, knowledge of MTCT and its prevention was found to be positively associated with PITC acceptance. This finding is in line with 2 more studies in Ethiopia. ${ }^{23,27}$ Women who have low level of knowledge of MTCT and its prevention method might not understand the value of PITC in preventing the transmission of the virus from mother to child, and consider PITC as an obligatory part of antenatal care service, which compromises their acceptance of PITC.

Perceived quality of PITC service was the core part of the program. We found a positive association between perceived quality of service and PITC acceptance, consistent with a similar study in Ethiopia. ${ }^{10}$ Pregnant women who perceive a better quality of service are more likely to accept PITC since they are attracted by the good quality of service delivered by the health professionals or the health professionals influence them to accept HIV testing as it is very important in preventing the transmission of the virus from mothers to children.

Considering the high HIV prevalence and despite the effective treatment available in this region, it is a matter of great concern that nearly one-third of the respondents refuse PITC. Based on our findings, interventions suggested to improve HIV detection and treatment among pregnant women are as follows: 1) pregnant women should be asked for HIV testing more than once during the antenatal care visits. Some women may not accept the HIV test at their first visit, but may change their minds at later visits; 2) younger women often have little experience and knowledge of PMTCT and need more support and instructions on PITC; 3) women's knowledge of MTCT and partner attitudes are related to women's acceptance of HIV testing. PMTCT education should be integrated into the routine antenatal care service. Meanwhile, persuading partners to involve themselves in counseling is strongly encouraged if applicable; 4) quality of PITC service should be improved in the future to promote the women's compliance with PITC. Strategies may include training counselors to improve their service capabilities, and provide culturally sensitive service according the ethnic background of pregnant women.

There are limitations in this study. First, it was a crosssectional study in which causal relationship could not be assessed. Second, the interview was conducted based on the pregnant women's perspectives, which may not reflect the whole picture of PITC service. Therefore, provider characteristics and program information should be included and evaluated in the future study.

In conclusion, it is essential to increase PITC acceptance through establishing PMTCT service centers with fully equipped necessary facilities and qualified health providers. This study offers suggestions on who should be the target population. Novel interventions are needed, especially among the subgroups of women who are least likely to take HIV test. Given the effective treatment for PMTCT, it is paramount that every HIV-positive pregnant woman has access to it and the best chance to deliver a healthy baby. 


\section{Disclosure}

The authors report no conflicts of interest in this work.

\section{References}

1. Manjate Cuco RM, Munguambe K, Bique Osman N, Degomme O, Temmerman M, Sidat MM. Male partners' involvement in prevention of mother-to-child HIV transmission in sub-Saharan Africa: a systematic review. SAHARA J. 2015;12(1):87-105.

2. Tudor Car L, Brusamento S, Elmoniry H, et al. The uptake of integrated perinatal prevention of mother-to-child HIV transmission programs in low- and middle-income countries: a systematic review. PLoS One. 2013;8(3):e56550.

3. Ethiopian Federal HIV/AIDS Prevention and Control Office, HIV/AIDS Estimates and Projections in Ethiopia, 2011-2016, 2016. Available from: http://www.aarc.gov.et/images/hivaidsprevalenceestimate.pdf. Accessed March 6, 2017.

4. Ethiopian Federal Ministry of Health, Country progress report on the HIV response, 2014. Available from: http://www.unaids.org/sites/ default/files/country documents/ETH_narrative_report_2014.pdf. Accessed February 4, 2017.

5. UNICEF. Elimination of New HIV Infections Among Children by 2015 And Keeping Their Mothers Alive. 2011. Available from: https://www unicef.org/french/aids/files/hivpmtctfactsheetEthiopia.pdf. Accessed March 21, 2017.

6. Sarkate P, Paranjpe S, Ingole N, Mehta P. Monitoring HIV epidemic in pregnant women: are the current measures enough? J Sex Transm Dis. 2015;2015:194831.

7. Asefa A, Mitike G. Prevention of mother-to-child transmission (PMTCT) of HIV services in Adama town, Ethiopia: clients' satisfaction and challenges experienced by service providers. BMC Pregnancy Childbirth. 2014;14:57.

8. Intra Health International, Fighting Pediatric HIV Infection in Ethiopia with PMTCT; 2012. Available from: https://www.intrahealth.org/features/fighting-pediatric-hiv-infection-ethiopia-pmtct. Accessed March 21, 2017.

9. Federal Ministry of Health, National training package of providerinitiated HIV testing and counseling, 2010. Available from: http://www etharc.org/index.php/resources/download/finish/33/422. Accessed March 21, 2017.

10. Abtew S, Awoke W, Asrat A. Acceptability of provider-initiated HIV testing as an intervention for prevention of mother to child transmission of HIV and associated factors among pregnant women attending at Public Health Facilities in Assosa town, Northwest Ethiopia. BMC Res Notes. 2015;8:661.

11. Fetene NW, Feleke AD. Missed opportunities for earlier HIV testing and diagnosis at the health facilities of Dessie town, North East Ethiopia. BMC Public Health. 2010;10:362.

12. Hensen B, Baggaley R, Wong VJ, et al. Universal voluntary HIV testing in antenatal care settings: a review of the contribution of provider-initiated testing \& counselling. Trop Med Int Health. 2012;17(1):59-70.

13. Becker J, Tsague L, Sahabo R, Twyman P. Provider initiated testing and counseling (PITC) for HIV in resource-limited clinical settings: important questions unanswered. Pan Afr Med J. 2009;3:4.
14. Ethiopian Federal Ministry of Health, Demographic and Health Survey; 2011. Available from: https://dhsprogram.com/pubs/pdf/SR191/SR191. pdf. Accessed February 16, 2017.

15. Hasen T. Acceptability of provider initiated HIV counseling and testing in pregnant mothers attending ANC at Nekemte Town Government Health Facilities. Sci Technol Arts Res J. 2012;1(3):24-30.

16. Malaju MT, Alene GD. Assessment of utilization of provider-initiated HIV testing and counseling as an intervention for prevention of mother to child transmission of HIV and associated factors among pregnant women in Gondar town, North West Ethiopia. BMC Public Health. 2012;12:226.

17. Hochbaum GM. Health Belief Model (HBM); 1958. Available from: http://www.med.uottawa.ca/courses/epi6181/images/Health_Belief_ Model_review.pdf. Accessed February 16, 2017.

18. Federal Democratic Republic of Ethiopia, The population of the regions of Ethiopia according to census results and latest official projections; 2015. Available from: https://www.citypopulation.de/Ethiopia.html. Accessed March 3, 2017.

19. Ethiopian Oromia Health Bureau. Reproductive, Maternal, Newborn, Childhood, Adolescent Health and Nutrition [RMNCAH-N] Annual Performance Report. Health Service Promotion Sub-process; 2016:21-22.

20. Ethiopian Federal HIV/AIDS Prevention and Control Office, Ethiopian prevention of mother to child transmission of HIV guide line, 2011 Available from: http://www.emtct-iatt.org/wpcontent/uploads/2016/01/ Ethiopia prevention of mother to child transmission of HIVguidelines 20111432359111.pdf. Accessed March 21, 2017.

21. Majid T, Farhad Y, Sorour A, et al. Preventing mother-to-child transmission of HIV/AIDS: do Iranian pregnant mothers know about it? $J$ Reprod Infertil. 2010;11(1):53-57.

22. Mujumali N. Knowledge and attitude on prevention of mother to child transmission of HIV among pregnant women attending reproductive and child health clinic at Temeke district hospital in dar es salaam. Muhimbili University of Health and Allied Sciences, 2010. Available from: http://ihi.eprints.org/id/eprint/1023. Accessed March 21, 2017.

23. Abdurahman S, Seyoum B, Oljira L, Weldegebreal F. Factors affecting acceptance of provider-initiated HIV testing and counseling services among outpatient clients in selected health facilities in Harar Town, Eastern Ethiopia. HIV AIDS (Auckl). 2015;7:157-165.

24. Dalal S, Lee CW, Farirai T, et al. Provider-initiated HIV testing and counseling: increased uptake in two public community health centers in South Africa and implications for scale-up. PLoS One. 2011; 6(11):e27293.

25. Makgahlela MW. The effect of stigma on HIV and AIDS testing uptake among pregnant women in Limpopo Province, 2010. Available from: http://hdl.handle.net/10386/291. Accessed March 21, 2017.

26. Kongnyuy EJ, Mbu ER, Mbopi-Keou FX, et al. Acceptability of intrapartum HIV counselling and testing in Cameroon. BMC Pregnancy Childbirth. 2009;9:9.

27. Demissie A, Deribew A, Abera M. Determinants of acceptance of voluntary HIV testing among antenatal clinic attendees at Dil Chora Hospital, Dire Dawa, East Ethiopia. Ethiop. J Health Dev. 2009;23(2).
Patient Preference and Adherence

\section{Publish your work in this journal}

Patient Preference and Adherence is an international, peer-reviewed, open access journal that focuses on the growing importance of patient preference and adherence throughout the therapeutic continuum. Patient satisfaction, acceptability, quality of life, compliance, persistence and their role in developing new therapeutic modalities and compounds to optimize

\section{Dovepress}

clinical outcomes for existing disease states are major areas of interest for the journal. This journal has been accepted for indexing on PubMed Central. The manuscript management system is completely online and includes a very quick and fair peer-review system, which is all easy to use. Visit http://www. dovepress.com/testimonials.php to read real quotes from published authors. 